\title{
Plasma viscosity in giant cell arteritis as a predictor of disease activity
}

\author{
M Gudmundsson, E Nordborg, B- $\AA \AA$ Bengtsson, A Bjelle
}

\begin{abstract}
Thirty one patients with giant cell arteritis (GCA) receiving standardised prednisolone treatment were followed up for one year with analyses of plasma viscosity, erythrocyte sedimentation rate (ESR), C reactive protein (CRP), and fibrinogen concentration. On the day of diagnosis all patients had an increased plasma viscosity and ESR, whereas the concentration of CRP was normal in three patients and fibrinogen concentration and haptoglobin values were normal in one patient. IgG levels were increased in two patients. Plasma viscosity correlated significantly with the ESR, IgG level, and fibrinogen concentration. Laboratory variables in subgroups of patients with GCA proved by biopsy were not different from the whole group of patients with GCA. The follow up showed that CRP normalised faster than the ESR, plasma viscosity, and fibrinogen concentration. Plasma viscosity and the ESR paralleled clinical findings more closely and predicted flare ups better than the other variables. Plasma viscosity had advantages over the ESR for predicting flare ups and in the clinical monitoring of treatment with glucocorticoids.
\end{abstract}

(Ann Rheum Dis 1993; 52: 104-109)

Giant cell arteritis (GCA) is a clinically heterogeneous syndrome of unknown aetiology and associated with a considerable systemic inflammatory reaction. ${ }^{12}$ The erythrocyte sedimentation rate (ESR) has long been generally recommended in the clinical monitoring of this disease, ${ }^{3-7}$ even in comparison with other acute phase reactants such as $C$ reactive protein (CRP). ${ }^{4-7}$ Although the ESR is usually increased in patients with GCA before treatment, ${ }^{7}$ normal values have been reported in $25 \%$ of patients. ${ }^{8}$ Of particular concern is the occurrence of normal ESR values even in fulminant cases of GCA. ${ }^{29}$ Another problem is the failure of the ESR to predict relapses. ${ }^{10}$ So far, no laboratory test has been found unfailingly to predict the severity of the disease ${ }^{2}$ and the judgement therefore still has to be based on clinical findings. ${ }^{2} 10$

Changes in blood rheology could be expected in GCA due to the increased protein concentrations-for example, of fibrinogen. ${ }^{11}$ Four previous studies have shown increased plasma viscosity in patients with GCA, ${ }^{12-15}$ whereas no changes in whole blood viscosity or in the rheological properties of erythrocytes have been found. ${ }^{15}$ Plasma viscosity has not been shown to be superior to the ESR in the monitoring of $\mathrm{GCA}^{35}$ but its value has not yet been tested in a longitudinal study of patients receiving a uniform therapeutic regimen.

The aim of this study was to evaluate prospectively the clinical significance of plasma viscosity compared with acute phase reactants in the clinical monitoring of GCA. Thirty one patients with GCA were followed from the early phase and during the first year of standard prednisolone treatment.

\section{Patients and methods}

PATIENTS

Thirty one consecutive patients with the diagnosis of GCA (seven men, 24 women) were included. The mean age was 67 years (range 58-81) for men and 72 (range 51-87) for women. Heavy smokers were excluded and none had any obvious signs of cardiovascular disease. One patient had been diabetic for one year but only needed dietary treatment. The duration of symptoms before diagnosis was on average 11 weeks (range 5-30 weeks).

All patients were admitted to hospital for general physical and laboratory examinations. They were examined and followed up by the same rheumatologist (EN). Biopsy samples, generally 5-10 $\mathrm{mm}$ long, were taken from the superficial temporal artery and fixed in a phosphate buffered $4 \%$ formaldehyde solution. After embedding in paraffin, 10-20 cross sections from each specimen were examined by light microscopy according to criteria given in the following.

Prednisolone was administered in a single morning dose (fig 1) starting with $40 \mathrm{mg}$ daily the first week, decreasing to $25 \mathrm{mg}$ daily the second week, and then reducing to the lowest effective maintenance dose on the basis of the clinical response. One patient received a lower prednisolone dose because of a diagnosis of diabetes.

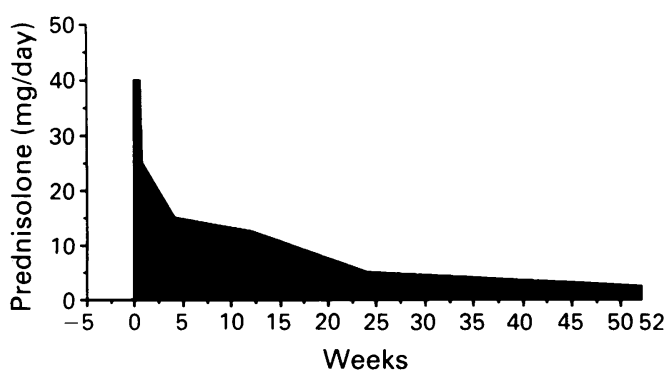

Figure 1. Prednisolone treatment schedule during the observation period of 52 weeks.

\author{
Sahlgren University Hosp \\ Sweden. \\ Accepted for publication \\ 9 September 1992. \\ Gothenburg \\ Correspondence to: \\ Dr Magnus Gudmundsson, \\ Department of
}


Ten patients had flare ups during treatment. A flare up was defined as symptoms of the disease requiring an increase in the dose of prednisolone. Thirteen consecutive patients without flare ups were selected for comparison. No flare up was defined as the absence of symptoms of disease at two consecutive visits of the patients receiving a constant low glucocorticoid dose of prednisolone ( $\leqslant 10 \mathrm{mg}$ daily).

\section{CRITERIA FOR GIANT CELL ARTERITIS}

The histopathological diagnosis of GCA was made when arteritis characterised by an interruption of the internal elastic membrane and infiltration of mononuclear cells in the arterial wall was observed in a temporal artery biospy sample.

Patients without histopathological findings of arteritis fulfilled the following criteria according to Bengtsson and Malmvall. ${ }^{16}$ (1) ESR $\geqslant 40$ $\mathrm{mm} /$ hour, age $\geqslant 50$ years and a prompt and long lasting response to glucocorticoid treatment. Patients with clinical or laboratory evidence of infection, malignant disease, rheumatoid arthritis, lupus erythematosus, or periarteritis nodosa were excluded. (2) Either or both of the following: (a) symptoms from the temporal region such as headache, scalp tenderness, jaw claudication, tenderness or swelling, or both, of the temporal artery, anterior ischaemic optic neuropathy; (b) (i) pain and stiffness affecting at least two large groups of proximal muscles (neck, shoulders/upper arms, hips, and thighs); (ii) morning stiffness of more than one hour; and (iii) duration of symptoms for more than two weeks.

\section{CLINICAL CLASSIFICATION OF GIANT CELL}

\section{ARTERITIS}

At the time of diagnosis patients were classified into four groups (table 1) ${ }^{16}$ : temporal arteritis according to criteria $2 a$; polymyalgia rheumatica according to criteria $2 b$; both temporal arteritis and polymyalgia rheumatica; and general symptoms - for example, fever, fatigue and malaise but not fulfilling the criteria of temporal arteritis or polymyalgia rheumatica ( $2 a$ or $2 b$ ).

\section{BLOOD SAMPLES}

Blood samples were collected at $0800 \mathrm{~h}$ and drawn from the antecubital vein with the subject in the sitting position. For the determination of plasma viscosity, $2.5 \mathrm{ml} 0.0034 \mathrm{M}$
EDTA $(1 \cdot 143 \mathrm{mg} / \mathrm{ml})$ was used as an anticoagulant and plasma was obtained by centrifugation for $10 \mathrm{minutes}$ at $3700 \mathrm{rev} / \mathrm{min}$.

\section{VISCOMETRY}

Plasma viscosity was measured within one hour of venepuncture by a Couette rotational viscometer (Bohlin, Lund) at a constant temperature of $27^{\circ} \mathrm{C}$ and a shear rate of $583 / \mathrm{s} .{ }^{17}$ The normal range was $1.55-1.75 \mathrm{mPa}$ s. ${ }^{17}$ The methodological recommendations of the International Committee for Standardization in Haematology (ICSH) were followed. ${ }^{18}$

\section{LABORATORY TESTS}

The ESR was measured by the Westergren method, fibrinogen concentration by a synoresis method, ${ }^{19}$ and CRP by the method of Mancini. IgG and haptoglobin levels were measured by the Cobas Fara immunoturbimetric method. The normal range for the ESR was $<20$ $\mathrm{mm}$ /hour for men and $<30 \mathrm{~mm} /$ hour for women. ${ }^{20}$ The normal ranges at our clinical laboratory were $2-4 \mathrm{~g} / \mathrm{l}$ for fibrinogen concentration, 7-17 g/l for IgG, $0 \cdot 4-1 \cdot 8 \mathrm{~g} / 1$ for haptoglobin, and $0-10 \mu \mathrm{g} / \mathrm{l}$ for CRP.

\section{STATISTICAL METHODS}

The $t$ test was used for comparisons between groups. Pearson correlation coefficients were used to measure the degree of association. The probability of flare up within the first year and after the first month of high dose glucocorticoid treatment was estimated by logistic regression analysis as a function of the ESR, plasma viscosity, or both. The corresponding curve equals the derivative of the receiver operating characteristic curve. ${ }^{21}$ To obtain these curves, the probability of a flare up within the first year of treatment was estimated without consideration of the ESR or plasma viscosity. The hazard function was approximated by a piecewise constant function. The expected proportions of patients with flare up when increasing the glucocorticoid dose at different levels of plasma viscosity, ESR, or these tests combined were calculated from these data.

\section{Results}

Eight of the 31 patients had GCA as proved by taking a biopsy sample (table 1). No significant differences were observed with respect to plasma

Table 1 Distribution of four clinical subgroups in 31 patients with giant cell arteritis (GCA), number of patients with GCA proved by taking a biopsy sample, and mean plasma viscosity in the respective diagnostic group. No significant differences of plasma viscosity levels were found between sexes, diagnostic subgroups, or between patients with and those without GCA proved by a biopsy sample

\begin{tabular}{llll}
\hline Clinical subgroup & No of men/women & $\begin{array}{l}\text { No of men/women } \\
\text { with biopsy proved GCA }\end{array}$ & $\begin{array}{c}\text { Mean (SE) plasma } \\
\text { viscosity (mPa s) }\end{array}$ \\
\hline $\begin{array}{l}\text { Temporal arteritis }(\mathrm{n}=6) \\
\text { Polymyalgia rheumatica }(\mathrm{n}=20)\end{array}$ & $1 / 5$ & $1 / 4$ & $2 \cdot 21(0 \cdot 110)$ \\
$\begin{array}{l}\text { Both temporal arteritis and } \\
\text { polymyalgia rheumatica }(\mathrm{n}=4)\end{array}$ & $6 / 14$ & $0 / 1$ & $2 \cdot 09(0 \cdot 048)$ \\
General symptoms $(\mathrm{n}=1)$ & $1 / 3$ & $0 / 1$ & $2 \cdot 15(0 \cdot 097)$ \\
Total $(\mathrm{n}=31)$ & $0 / 1$ & $0 / 1$ & $1 \cdot 87$ \\
\hline
\end{tabular}


Table 2 Correlations between plasma viscosity $(P V)$ erythrocyte sedimentation rate $(E S R), C$ reactive protein (CRP), fibrinogen concentration (FC), haptoglobin, immunoglobulin $G(I g G)$ and symptom duration in 31 patients with giant cell arteritis before treatment

\begin{tabular}{|c|c|c|c|c|c|c|c|c|c|c|c|c|}
\hline \multirow{2}{*}{$\begin{array}{l}\text { Laboratory } \\
\text { variable }\end{array}$} & \multicolumn{2}{|c|}{$E S R$} & \multicolumn{2}{|c|}{$C R P$} & \multicolumn{2}{|l|}{$F C$} & \multicolumn{2}{|c|}{ Haptoglobin } & \multicolumn{2}{|l|}{$\operatorname{Ig} G$} & \multicolumn{2}{|c|}{$\begin{array}{l}\text { Symptom } \\
\text { duration }\end{array}$} \\
\hline & No & $r$ Value & No & $r$ Value & No & $r$ Value & No & $r$ Value & No & $r$ Value & No & $r$ Value \\
\hline $\begin{array}{l}\text { PV (mPa s) } \\
\text { ESR (mm/hour) } \\
\text { CRP }(\mu \mathrm{g} / \mathbf{l}) \\
\text { FC }(\mathrm{g} / \mathrm{l}) \\
\text { Haptoglobin }(\mathrm{g} / \mathrm{l}) \\
\text { IgG (g/l) }\end{array}$ & & $0.5^{* *}$ & $\begin{array}{l}27 \\
27\end{array}$ & $\begin{array}{l}0 \cdot 2 \\
0 \cdot 4\end{array}$ & $\begin{array}{l}20 \\
21 \\
19\end{array}$ & $\begin{array}{l}0 \cdot 6^{*} \\
0 \cdot 7^{\text {*****: }} \\
0 \cdot 7^{\text {*** }}\end{array}$ & $\begin{array}{l}21 \\
21 \\
21 \\
15\end{array}$ & $\begin{array}{l}0.5^{*} \\
0 \cdot 4 \\
0 \cdot 5^{*} \\
0.6^{*}\end{array}$ & $\begin{array}{l}20 \\
20 \\
19 \\
14 \\
18\end{array}$ & $\begin{array}{c}0.6^{* *} \\
0.5^{*} \\
0 \cdot 1 \\
0.4 \\
-0.1\end{array}$ & $\begin{array}{l}30 \\
30 \\
28 \\
20 \\
21 \\
19\end{array}$ & $\begin{array}{l}-0 \cdot 2 \\
-0.2 \\
-0 \cdot 4^{*} \\
-0 \cdot 2 \\
-0 \cdot 2 \\
0.2\end{array}$ \\
\hline
\end{tabular}

${ }^{*} \mathrm{p}<0.05 ;{ }^{* *} \mathrm{p}<0.01 ;$ and ${ }^{* * *} \mathrm{p}<0.001$.

viscosity, ESR, CRP, and fibrinogen concentration between patients with symptoms of temporal arteritis and those with symptoms of polymyalgia rheumatica at the time of diagnosis. Nor were there any significant differences between patients with and those without biopsy findings of GCA (table 1).

Before treatment, all patients had increased levels of plasma viscosity (range 1.83-2.86 $\mathrm{mPa} \mathrm{s}$ ) and ESR (range $35-135 \mathrm{~mm} /$ hour). In three patients CRP was not increased, and the fibrinogen concentration was normal in one patient. Haptoglobin was normal in one patient and the IgG concentration was increased in only two patients. Mean (SD) values before treatment (day zero) are given in the following.

Before treatment, plasma viscosity correlated significantly with ESR $(r=0.5 ; p<0.01)$,

Table 3 Comparisons of some laboratory variables (plasma viscosity (PV), erythrocyte sedimentation rate $(E S R), C$ reactive protein $(C R P))$ and daily prednisolone dose between patients with and without flare ups

\begin{tabular}{|c|c|c|c|c|c|}
\hline & \multicolumn{2}{|c|}{ Patients with flare ups } & \multicolumn{2}{|c|}{$\begin{array}{l}\text { Patients without } \\
\text { flare ups }\end{array}$} & \multirow[t]{2}{*}{$\begin{array}{l}\text { Significance of } \\
\text { difference }\end{array}$} \\
\hline & No & Mean $(S E)$ & No & Mean $(S E)$ & \\
\hline $\begin{array}{l}\text { Laboratory tests } \\
\text { PV (mPa s) } \\
\text { ESR (mm/hour) } \\
\text { CRP ( } \mu \mathrm{g} / \mathrm{l}) \\
\text { Prednisolone (mg/day) }\end{array}$ & $\begin{array}{r}10 \\
10 \\
7 \\
10\end{array}$ & $\begin{array}{l}1 \cdot 96(0 \cdot 068) \\
35(8 \cdot 0) \\
7 \cdot 2(2 \cdot 2) \\
12(2 \cdot 8)\end{array}$ & $\begin{array}{r}13 \\
10 \\
9 \\
13\end{array}$ & $\begin{array}{l}1 \cdot 75(0 \cdot 027) \\
12(1 \cdot 7) \\
6 \cdot 0(1 \cdot 0) \\
6(0 \cdot 9)\end{array}$ & $\begin{array}{l}\mathrm{p}<0.01 \\
\mathrm{p}<0.05 \\
\mathrm{NS} \\
\mathrm{p}<0.05\end{array}$ \\
\hline
\end{tabular}

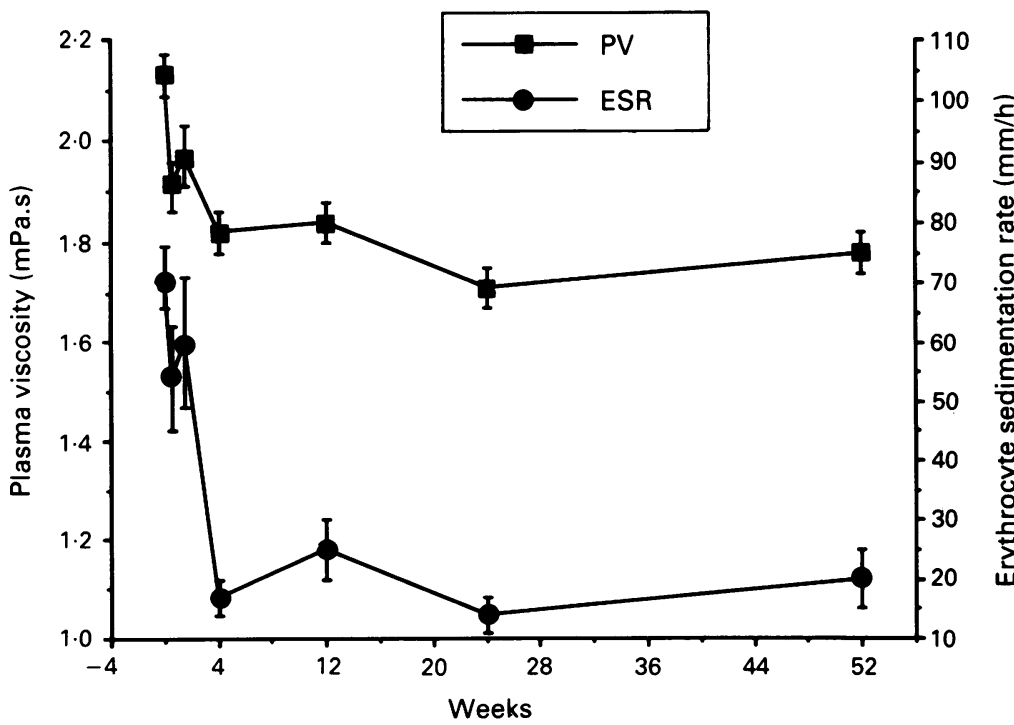

Figure 2 Mean values with standard errors (vertical lines) of plasma viscosity and erythrocyte sedimentation rate at days 4 and 10 and at weeks $4,12,24$, and 52 . fibrinogen concentration $(r=0.6 ; \mathrm{p}<0.05)$, haptoglobin $(r=0.5 ; p<0.05)$, and IgG $(r=0.6$; $\mathrm{p}<0 \cdot 01)$. C reactive protein correlated with fibrinogen concentration $(r=0.7 ; p<0.01)$ but not with ESR $(r=0 \cdot 4$; NS). The erythrocyte sedimentation rate correlated with fibrinogen concentration $(r=0.7 ; p<0.001)$ and with IgG $(\mathrm{r}=0.5 ; \mathrm{p}<0.05)$. The duration of symptoms showed no significant correlation with any of the laboratory variables except for a negative correlation with CRP $(\mathrm{p}<0.05)$ (table 2). Multiple regression with plasma viscosity as the dependent variable showed that IgG was the strongest independent variable, followed by the ESR. With two independent variables, fibrinogen concentration and erythrocyte sedimentation rate, the regression was significant $(r=0.6$; $p<0.05$ ) but neither of the two independent variables reached significant levels, probably because they are strongly interrelated. Correlation analysis for plasma viscosity with other laboratory variables while controlling for fibrinogen concentration showed that only IgG correlated significantly $(r=0.6 ; p<0.05)$. Controlling for IgG showed significant correlation only between haptoglobin and plasma viscosity $(r=0.6 ; p<0.05)$.

After four days of treatment, significantly lower values of laboratory tests were found for all variables except ESR (figs 2 and 3). The mean (SD) value of plasma viscosity at day zero was $2 \cdot 13(0.225) \mathrm{mPa} s$ and at day four 1.92 $(0.160) \mathrm{mPa} s(\mathrm{p}<0.01)$. The mean (SD) ESR at day zero was $71(28 \cdot 1) \mathrm{mm} /$ hour and at day four $54(28 \cdot 1) \mathrm{mm} /$ hour (NS). C reactive protein at day zero was $53(34.9) \mu \mathrm{g} / \mathrm{l}$ and at day four 24 $(20: 4) \mathrm{mg} / \mathrm{l}(\mathrm{p}<0.05)$ and fibrinogen concentration at day zero was $6.1(1.34) \mathrm{g} / \mathrm{l}$ and at day four $4.3(1.01) \mathrm{g} / \mathrm{l}(\mathrm{p}<0.01)$. After 10 days of treatment we observed an upwards drift in plasma viscosity and ESR (fig 1) but there was no significant difference between days four and ten. This was not found for fibrinogen concentration or CRP. Clinically, however, there was no sign of flare ups at day ten.

$C$ reactive protein tended to decrease faster than any other laboratory variable and all patients had normal values after three weeks (fig 3). Plasma viscosity showed significant changes earlier than the ESR (at day four) but the ESR decreased faster than the plasma viscosity as the treatment progressed (fig 2). After 10 days of treatment, $72 \%$ of the patients had normal values of CRP, whereas $26 \%$ had normal plasma 
viscosity, $25 \%$ a normal $\mathrm{ESR}$, and $4 \%$ a normal fibrinogen concentration. After four weeks of treatment, all patients had normal values of CRP, whereas $40 \%$ had normal plasma viscosity, $61 \%$ a normal ESR, and $33 \%$ a normal fibrinogen concentration.

Significantly higher values for plasma viscosity
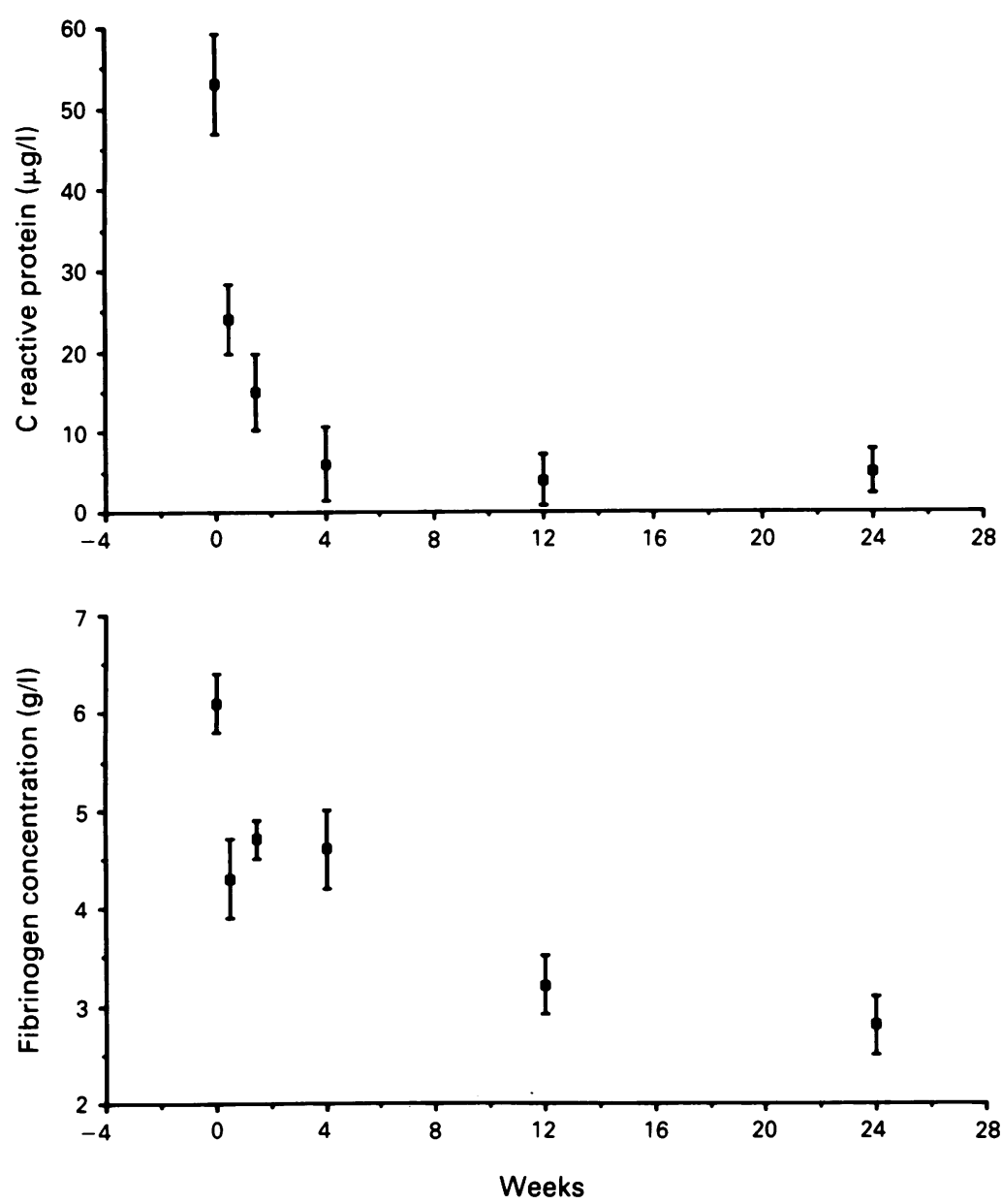

Figure 3 Mean values with standard errors (vertical lines) of $C$ reactive protein and fibrinogen concentration at days 4 and 10 and at weeks 4,12 , and 24

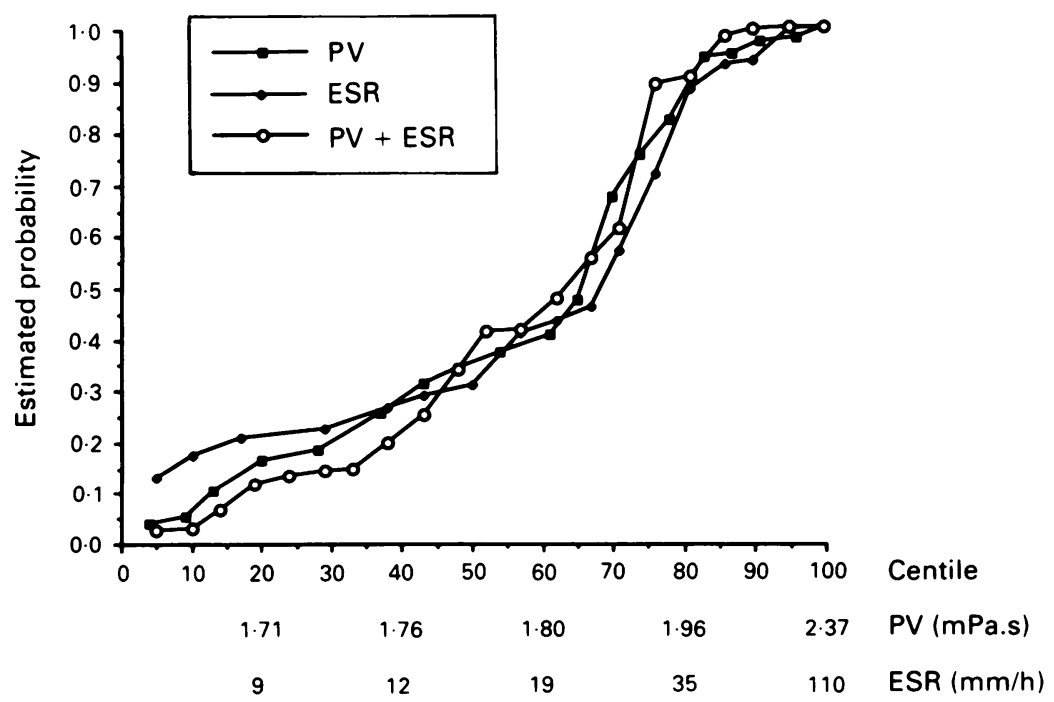

Figure 4 Probability of developing a flare up estimated by logistic regression analysis. Erythrocyte sedimentation rate $(E S R)$ and plasma viscosity $(P V)$ are shown as centile points on the abscissa. Values of ESR and PV corresponding to the respective centile are shown. and the ESR but not for CRP were found in the 10 patients showing flare ups compared with the 13 patients without flare ups (table 3). By logistic regression analysis the optimum linear combination of ESR and plasma viscosity for predicting flare up was 0.094 ESR+0.021 PV. The logistic regression analysis showed no overall preference between plasma viscosity, ESR, or both in predicting flare ups (fig 4).

Using the hazard function, the probability of flare up within the first year and after the first month of high dose glucocorticoid treatment was determined to be $0 \cdot 50$. The use of different levels of plasma viscosity, ESR, or the two tests combined to lower the proportion of patients developing a flare up by increasing the glucocorticoid dose was exemplified by the following estimates. The calculations were based on the successful treatment of 60,50 , and $40 \%$ of patients, corresponding to centiles 40,50 , and 60 respectively (fig 4). Using the ESR to make the decision to increase the glucocorticoid dose, the proportion of patients with a flare up during the first year of treatment would be reduced to $8 \%$ at a ESR of $12 \mathrm{~mm} /$ hour, $10 \%$ at an ESR of $14 \mathrm{~mm} / \mathrm{hour}$, and $14 \%$ at an ESR of $19 \mathrm{~mm} /$ hour. The corresponding values for plasma viscosity were $6 \%$ at $1.76 \mathrm{mPa} \mathrm{s}, 9 \%$ at $1.78 \mathrm{mPa}$ s, and $13 \%$ at $1.80 \mathrm{mPa}$. Combining the two tests would result in $4 \%$ flare ups increasing glucocorticoids at the 40th centile (ESR $12 \mathrm{~mm} /$ hour; plasma viscosity 1.76 $\mathrm{mPa} \mathrm{s}$ ), $7 \%$ at the 50 th (ESR $14 \mathrm{~mm} /$ hour; plasma viscosity $1.78 \mathrm{mPa} \mathrm{s}$ ) and $11 \%$ at the 60th centile (ESR $19 \mathrm{~mm} /$ hour; plasma viscosity $1.80 \mathrm{mPa} \mathrm{s}$ ). This is within the normal range for ESR, whereas the level of plasma viscosity is just above the normal range. Increasing glucocorticoids at an ESR of $23 \mathrm{~mm} /$ hour (70th centile), $19 \%$ of patients would develop a flare up.

\section{Discussion}

Before treatment, plasma viscosity and ESR values were increased in all patients, whereas normal fibrinogen concentration and haptoglobin concentrations were observed in one patient, and normal CRP in three patients. No significant differences were observed in any laboratory variable between the clinical subgroups of GCA. Plasma viscosity correlated significantly with ESR, haptoglobin, fibrinogen concentration, and IgG. The risk of flare up within the first year on a fixed therapeutic schedule could be reduced using the ESR and plasma viscosity as indicators for a prophylactic increase of the glucocorticoid dose. As the plasma viscosity value coincides with the upper normal value whereas the ESR value is within the normal range, the plasma viscosity is preferable to ESR for the monitoring of GCA.

A rotational viscometer was used in this study. ${ }^{17}$ It was previously shown to be in accordance with the recommendation of the $\mathrm{ICSH},{ }^{18}$ yielding almost identical accuracy to the Harkness capillary viscometer. ${ }^{17}$

A major difficulty in the evaluation of laboratory variables in previous studies is the clinical heterogeneity of the GCA syndrome and the 
lack of diagnostic tests. ${ }^{1} 21622$ A negative biopsy sample does not exclude the clinical diagnosis of $\mathrm{GCA}^{122}$ and the morphological criteria for GCA may have to be revised. ${ }^{23}$ This study did not show the laboratory tests available to be of any diagnostic value in separating clinical GCA subgroups, nor could the tests separate patients with positive from those with negative biospies. These findings support previous studies where attempts to separate patient subgroups by laboratory tests have failed. ${ }^{1-15} 22$

The value of plasma viscosity compared with ESR in the diagnosis of GCA could not be evaluated from previous studies. ${ }^{12-15}$ One patient with normal plasma viscosity has been reported in a study of nine patients with GCA. ${ }^{14}$ The ESR or other laboratory variables were not given for this patient and the diagnosis was not confirmed by a biopsy sample of the temporal artery. None of our patients had a plasma viscosity within the normal range before treatment but further experience is required to establish the value of plasma viscosity in the diagnosis of GCA. C reactive protein was not suitable for monitoring treatment in GCA as it was within the normal range in $10 \%$ of our patients before treatment and inferior to ESR and plasma viscosity in predicting exacerbations.

The question of how to balance glucocorticoid treatment to control the disease with a minimum of side effects is still controversial, partly due to the variable experience of different medical specialties. ${ }^{1211162425}$ The highest risk of death in patients with GCA is during the first year, and particularly during the first months of disease. ${ }^{26}$ For this reason, the follow up tests were concentrated in the early phase of the disease in this study. In elderly patients at risk of a flare up the ESR was well within the normal range, ${ }^{20}$ whereas plasma viscosity was just above the normal range. ${ }^{17}$ Furthermore, plasma viscosity has been shown to vary less with factors other than disease (age, sex, and smoking habits) than the ESR. ${ }^{17} 27$ To the doctor, plasma viscosity thus offers advantages over the ESR in the monitoring of treatment in patients with GCA - that is, as an indicator for increasing the glucocorticoid dose in patients at risk of a flare up. One reason for the high exacerbation rate may in fact be that the ESR dose does not provide an adequate warning to the doctor.

Fibrinogen is generally considered to be one of the major contributors to the viscosity properties of plasma. ${ }^{28} 29$ In GCA it is regarded as an acute phase reactant ${ }^{11}$ which is usually increased. Fibrinogen is important in the inflammatory processes of the arteries ${ }^{23}$ and blood clotting factors have consequently been suspected to have a pathogenetic role in GCA. ${ }^{2}{ }^{30}$ The increased values of plasma viscosity in GCA were not in the range found in hyperviscosity syndromes, ${ }^{27} 28$ but may contribute to the vascular symptoms in this disease. No immunological test has been of clinical use in the diagnosis or monitoring of GCA. ${ }^{2} 31$ The future role of interleukin 6 has to be further evaluated. ${ }^{32}$

So far, the ESR has been shown to be superior to all other tests except plasma viscosity in the monitoring of GCA. The limited experi- ence of plasma viscosity compared with the ESR does not at this stage allow plasma viscosity to be used as a substitute for ESR in the diagnosis of GCA. In the monitoring of GCA, plasma viscosity offers advantages over the ESR. As plasma viscosity partly reflects pathogenetic factors other than ESR-factors of probable importance for the vascular complications in patients with GCA - further studies to evaluate the rheological factors in GCA are of great interest.

The skilful technical assistance of Mrs Eleni Andersson is greatly appreciated. We are grateful for the help of the staff and patient participating at the department of rheumatology, Sahlgre University Hospital, Gothenburg. Statistical advisers were Björn Areskoug and Anders Odén, $\mathrm{PhD}$. This study was supported by grants from Göteborgs Läkaresällskap and from Göteborgs Reumatikerförening.

1 Healey L A, Wilske $\mathrm{K}$ R. The systemic manifestations of

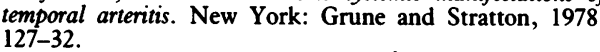

2 Nordborg E, Nordborg C, Bengtsson B- $\AA$. Giant cell arteritis. Curr Opin Rheumatol 1992; 4:23-30.

3 Paulsen S, Iversen Th $\mathrm{O}$. Rheumatic polymyalgia. Long-term treatment with steroids. Acta R heum Scand 1971; 17: 165-8.

4 Park J R, Jones J G, Hazleman B L. Relationship of erythrocyte sedimentation rate to acute phase proteins in poly myalgia rheumatica and giant cell arteritis. Ann Rheum $D$ 1981; 40: 493-5

5 Mallya R K, Hind C R K, Berry H, Pepys M B. Serum $\mathrm{C}$-reactive protein in polymyalgia rheumatica. A prospectiv serial study. Arthritis Rheum 1985; 28: 383-7.

6 Andersson R, Malmvall B E, Bengtsson B- $\AA$. Acute phas reactants in the initial phase of giant cell arteritis. Acta Med Scand 1986; 220: 365-7.

7 Kyle V, Cawston T E, Hazleman B L. Erythrocyte sedimentation rate and $\mathrm{C}$-reactive protein in the assessment of polymyalgia rheumatica/giant cell arteritis on presentation and during follow up. Ann Rheum Dis 1989; 48: 667-71.

8 Ellis M E, Ralston S. The ESR in the diagnosis and manage ment of the polymyalgia rheumatica/giant cell arteritis ment of the polymyalgia rheumatica/giant
syndrome. Ann Rheum Dis 1983;42: 168-70

9 Wise C M, Agudelo C A, Chmelewski W L, McKnight K M. Temporal arteritis with low erythrocyte sedimentation rate: a review of five cases. Arthritis Rheum 1991; 34: 1571-4.

10 Dare B, Byrne E. Giant cell arteritis. A five-year review of biopsy-proven cases in a teaching hospital. Med $\mathcal{J}$ Aus 1980; $1: 372-3$.

11 Miehle W. Polymyalgia arteritica (rheumatica). Wien Klin Wochenschr 1983; 24: 855-60.

12 Esselinckx W, Bucknall R C, Dixon A St J. Polymyalgia rheumatica. Assessment of disease activity using erythrocyte sedimentation rate and plasma viscosity. Ann Rheum Dis 1977; 36: 560-2.

13 Esselinckx W, Doherty S M, Dixon A St J. Polymyalgia rheumatica. Abrupt and gradual withdrawal of prednisolone treatment, clinical and laboratory observations. Ann Rheum Dis 1977; 36: 219-24.

14 Allison M C, Gough K R. Steroid sensitive systemic disease with anaemia in the elderly: a manifestation of giant cell arteritis? Postgrad Med F 1985; 61: 501-3.

15 Wiek J, Krause M, Wiederholt M, Hansen L L. Hämorheologische Parameter bei Patienten mit Riesenzellarteritis vo und nach der Behandlung mit Steroiden. Fortsch Ophthalmol 1990; 87: 671-4.

16 Bengtsson B- $\AA$, Malmvall B E. The epidemiology of giant cell arteritis including temporal arteritis and polymyalgia rheumatica. Incidences of different clinical presentations and eye complications. Arthritis Rheum 1981; 24: 899-904.

17 Gudmundsson M, Bjelle A. Plasma, serum and whole blood viscosity. Variation with age, sex and smoking habits. Angiology. In press.

18 Borovieczeny K G, Dintenfass L, Fukada E, et al. Recommendation for a selected method for the measurement of plasma viscosity. International Committee fo Standardization in Haematology. $\mathcal{f}$ Clin Pathol 1984; 37 $1147-52$.

19 Nilsson IM, Olow B. Determination of fibrinogen and fibrinolytic activity. Thromb Diath Haemorrh 1962; 8: 297-305.

20 Böttiger L E, Svedberg C A. Normal erythrocyte sedimentation rate and age. $B M F$ 1967; $2: 85-7$.

21 Hanley J A, McNeil B J. The meaning and use of the area under the receiver operating characteristic (ROC) curve. Radiology 1982; 143: 29-36.

22 Soelberg Sörensen P, Lorenzen I. Giant-cell arteritis, temporal arteritis and polymyalgia rheumatica. A retrospective study of 63 patients. Acta Med Scand 1977; 201 : 207-13.

23 Nordborg E, Bengtsson B- $\AA$, Nordborg C. Temporal artery morphology and morphometry in giant cell arteritis. Acto Pathol Microbiol Immunol Scand 1991; 99: 1013-23. 
24 Jones J G, Hazleman B L. Prognosis and management of polymyalgia rheumatica. Ann Rheum Dis 1981; 40: 1-5.

25 Myles A B, Perera T, Ridley M G. Prevention of blindness in giant cell arteritis by corticosteroid therapy. $\mathrm{Br} \mathcal{F}$ Rheumato 1992; 31: 103-5.

26 Nordborg E, Bengtsson B- $\AA$. Death rates and causes of death in 284 consecutive patients with giant cell arteritis confirmed by biopsy. $B M \mathcal{F} 1989 ; 299$ : $549-50$.

27 Harkness J. Rheological tests for monitoring disease activity Comparison of the E.S.R. and plasma viscosity tests. Clinical Hemorheology 1989; 9: 35-9.

28 Harkness J. The viscosity of human blood plasma; its measurement in health and disease. Biorheology 1971; 8: 171-93.
29 Dintenfass $\mathrm{L}$. Influence of plasma proteins on the in vivo and in vitro rheological properties of blood. Clinical Hemorheology 1985; 5: 191-206.

30 Nordborg E, Andersson R, Tengborn L, Edén S, Bengtsson $B \AA$. von Willebrand factor antigen and plasminogen activator inhibitor in giant cell arteritis. Ann Rheum Dis 1991; 50: 316-20.

31 Bengtsson B-A, Malmvall B E. Giant cell arteritis. Acta Med Scand 1982; suppl 658: 48-59.

32 Dasgupta B, Panayi GS. Interleukin-6 in serum in patients with polymyalgia rheumatica and giant cell arteritis. $B r$ with polymyalgia rheumatic 